\title{
Bio-softening of Coir Yarn for Ecofriendly Wet Processing
}

\author{
Anita Das Ravindranath and Chitralekha M
}

\begin{abstract}
Conventional chemical bleaching of coir generates a considerable amount of effluent which is discharged into the local water bodies thereby affecting the water quality there. The possibility of biobleaching and bio-softening of coir yarn in order to reduce the requirement of softening and bleaching chemicals in wet processing of coir was studied. Treatment of coir yarn for $72 \mathrm{hrs}$ using Trametes versicolor (NCIM 993) and Coirret, a bacterial consortium was carried out. The bio-treatment could impart an appreciable degree of softness to the yarn which was confirmed by the Flexural Rigidity Test. An improvement in softness of the yarn to the extent of $38 \%$ using bacterial treatment and $46 \%$ using fungal treatment was achieved. A noticeable change was observed in surface morphology of the fibre through SEM analysis. The lignin content of the fungal treated yarn was also reduced to some extent. An increase of $10 \%$ in Brightness Index of the fungi treated yarn was observed and a reduction in the requirement of bleaching chemicals could also be achieved. The physico-chemical parameters of the residual bleach liquor were also studied and a considerable decrease in BOD, COD and phenol content was observed.
\end{abstract}

Keywords: Coir yarn, Micro-organism, Eco-friendly, Coirret, Wet processing

Department of Microbiology, Central Coir Research Institute, Kalavoor, Alappuzha 688522, Kerala, India.

Email: anitadas30@gmail.com 


\section{Introduction}

Biotechnological interventions have proved to be a boon for solving the serious pollution problems faced by several industries like paper and leather industry. The environmental friendly biological treatments give them an edge over harsh polluting chemical treatments.

India is the largest producer of coconut in the world with a production of 15,840 million nuts per annum grown in an area of 1939.90 thousand hectares. Coir industry is of great importance in some areas of the developing countries like India, particularly the coastal regions of Kerala produces $60 \%$ of the total world supply of white coir fibre. The global annual production of coir fibre is about 350,000 metric tons (MT). Currently, the world's top two producers, India and Sri Lanka together account for about $90 \%$ of global coir fibre production. India is the world's larger exporter of value added products such as yarn, mats and rugs.

Coir fibre can be extracted from the husk by two ways - the traditional retting process and mechanical extraction. Traditional retting was a fibre recovery process carried out in the backwater lagoons. This method has disadvantages such as (i) labour intensiveness (ii) time consumption - husks should be immersed in back waters for 9-11 months and (iii) pollution of surface water. Various processes involved in coir processing like dyeing, bleaching, sludge disposal etc are deteriorating the quality of the lakes and other water bodies. The coir fibre and yarn used in coir industry for the production of mats, matting, runners, rugs and carpets are bleached using chemical bleaching methods which use a wide range of chemicals such as peroxides, hypochlorites, chlorites, peracids, sulphites, bisulphites, borohydrides, etc. (Anto, 1997a) Adopting biobleaching and biosoftening for wet processing of coir is an alternative to using hazardous chemical treatments.

Mechanically extracted fibre is comparatively rougher than the traditionally retted fibre. Emulsions of oil, fats and waxes, soaps, sulphonated oil, sulphated alcohols, fatty acid condensation products and quaternary ammonium compounds are the major classes of softening agents. (Anto, 1997b) The cheapest method for softening is alkaline treatment, which was effective to a certain extent, but was detrimental to the strength of the yarn. So far, an acceptable chemical softener for industrial use has not been found due to economical as well as environmental concerns. Bio-softening aims to achieve a bio-polishing effect with the use of specific microorganisms, with selected enzyme specificity towards surface cell wall components. The rigid lignin network between fibre cells prevents flexible behavior of the fibre. Softening of the fibre without affecting the fibre strength can be accomplished along with the bio-bleaching treatment, since the component responsible for the colour and stiffness are one and the same 'lignin'. Biosoftening of unretted coir fibre was more advantageous than the retted fibre. Unlike the weak chemically softened fibre, microbial treatment produced soft, brighter fibres having better tensile strength and elongation properties. (Rajan et al., 2005) Bio-softened coir fibre is spinnable and can be blended with other natural fibres like jute, sisal, banana for producing furnishing fabrics, textiles, etc. (Rajan and Abraham, 2007)

Lignin is the second most abundant natural polymer and forms a matrix surrounding the cellulose, the most abundant biopolymer. Basidiomycetes white-rot fungi are responsible for the most extensive biodegradation of lignin. They have a powerful extracellular enzymatic complex, capable of depolymerizing this aromatic polymer into lower molecular weight compounds. Phanerochaete chrysosporium is one of the most characterised white-rot fungus and Trametes versicolor has also been studied in details. (Ana Maria et al., 2007)

Trametes versicolor, formerly known as Coriolus versicolor is a typical lignin-degrading fungus. Wood pulp biobleaching by lignin degradation has been studied well with this white rot fungus. (Homma, 2007) They produce three main extracellular enzymes involved in ligninolysis; viz. laccase, lignin peroxidase and manganese peroxidase. Though all white rot fungi do not produce all three enzymes, laccase occupies an important place in ligninolysis. 
(Arora and Gill, 2001) T. versicolor or its enzymes have been reported to delignify and bleach kraft pulp and also efficiently dechlorinate and decolourise bleach kraft pulp effluent. (Ana Maria et al., 2007) Bio-softening of the mature coconut husk using Basidiomycetes fungi was faster and more efficient in degrading lignin and toxic phenolics. Phanerochaete chrysosporium, Pleurotus eryngii and Ceriporiopsis subvermispora degrade lignin efficiently without any appreciable loss of cellulose, yielding good quality fibre ideal for dyeing. (Suganya, et al., 2007)

Coirret is a patented bacterial formulation constituting of Mycoplana. bullata, Mycoplana dimorpha and Pseudomonas desmolyticum belong to the family Actinomycetes which possess the ability of degrading phenolic compounds. (Das, A.R., 2001)

The objectives of the present study was to evaluate the bio-bleaching and bio-softening efficiency of bacterial and fungal cultures on coir yarn and to combine bio-bleaching and chemical bleaching to check the feasibility of reduction of bleaching chemicals required and thereby reduce surface water pollution.

\section{Materials and methods}

\section{Biobleaching/Softening}

The coir yarn taken for the study was Anjengo yarn, properties of which are given in Table 1.

Table 1. Properties of Anjengo yarn

\begin{tabular}{|l|l|}
\hline Yarn Diameter & $3-6 \mathrm{~mm}$ \\
\hline Length & $200-300 \mathrm{~m} / \mathrm{kg}$ \\
\hline Nature of twist & Hard twist \\
\hline Quality & Superior \\
\hline
\end{tabular}

\section{Inoculum Preparation}

The pure cultures of Mycoplana bullata, Mycoplana dimorpha and Pseudomonas desmolyticum maintained in the Microbiology laboratory of CCRI were sub-cultured on nutrient agar slants and incubated at $37^{\circ} \mathrm{C}$ for 5 days to attain the maximum growth. These individual cultures were then inoculated into $200 \mathrm{ml}$ nutrient broth and incubated for 72 hours.

Trametes versicolor NCIM 993 was subcultured on Potato Dextrose Agar (PDA) slants and incubated at $30^{\circ} \mathrm{C}$ for 7 days. After seven days, the culture was inoculated into the optimized laccase production media and incubated at $30^{\circ} \mathrm{C}$ for 4 days. The optimum temperature and incubation period for laccase production by Trametes versicolor has been reported as $30^{\circ} \mathrm{C}$ and 4 days respectively. (Pazarlioglu et al., 2005)

The cell free culture fluid (cfcf) of Trametes versicolor was obtained by centrifuging the culture broth in ROTEK RMC6 centrifuge and filtering the supernatant through Whatman 40 filter paper.

\section{Experimental Design}

The coir yarn was soaked in water (material: liquor ratio of 1:20) maintaining an untreated control. The treatment flasks were inoculated with bacterial and fungal cultures and incubated at $37^{\circ} \mathrm{C}$ and room temperature respectively. The treatment was continued for 72 hours after which the yarn was carefully taken out of the flask, washed with water and air-dried. The surface of the treated yarn was scanned in the SEM to understand the change in surface morphology. Lignin content of the untreated and treated yarn was estimated. The softness and brightness of the treated yarn was assessed using Flexural Rigidity Tester and spectrophotometer respectively was conducted on the fungal treated yarn was chemical bleached and the $\mathrm{pH}$, phenol content, BOD and $\mathrm{COD}$ of the bleach liquor were estimated.

Standard recipe for regular bleaching of coir using hydrogen peroxide was adopted for chemical bleaching with a material: liquor ratio of $1: 15$ and treatment temperature of $85^{\circ} \mathrm{C}$ for an hour, after which, the yarn was drawn out, washed with cold water and air dried in the shade. 


\section{Flexural Rigidity Assessment of Coir Yarn}

Flexural Rigidity of the untreated, bacterial treated and fungal treated yarn was tested using the Flexural Rigidity Tester (developed by CCRI). Flexural rigidity test indirectly measures the degree of softness by evaluating the flexural rigidity of the fibre, when subjected to deformation. 25 samples each of raw, control and treated fibre were tied around a PVC pipe of 2 inch diameter to attain the shape of a ring. After 24 hours, the rings were tested using the Flexural Rigidity Tester with and without load (1g) and the ring diameter and deformation of ring on loading was noted. The average radius of the ring and deformation on loading were calculated. The Flexural Rigidity was calculated using the following formula:

\section{Flexural Rigidity $=0.0047 \mathrm{mg} .(2 \Pi \mathrm{r})^{2} \cos \varnothing / \tan \emptyset$ $\left(\mathrm{gcm}^{2}\right)$}

where, $\mathrm{mg}=$ weight of load applied in grams

$\mathrm{r}=$ radius of the ring in $\mathrm{cm}$

$\mathrm{d}=$ deformation of lower end of ring in $\mathrm{cm}$

$\varnothing=493 \mathrm{~d} / 2 \Pi \mathrm{r}$

\section{Scanning Electron Microscopic Study of Coir Yarn}

The surface morphology of the treated, untreated and control coir yarn were observed using Scanning Electron Microscope (SEM) JEOL JSM 6380LV.

\section{Estimation of Lignin in Fibre Samples by Acid Hydrolysis Method}

One gram of coir yarn/fibre was accurately weighed and cut into small pieces. Weighed coir yarn was packed in a whatman 1 filter paper and refluxed with ethanol-benzene mixture $(1: 2)$ in a Soxhlet extraction apparatus for 4 hours. After cooling, the fibre was filtered, washed with ethanol and dried in hot air oven. The dried sample was refluxed with $200 \mathrm{ml}$ boiling water for 4 hours in a round bottom flask attached to a Liebig condenser. It was then cooled, filtered and air-dried. The dried sample thus obtained was transferred to a $100 \mathrm{ml}$ beaker and carefully macerated into a fine paste with the addition of
$5 \mathrm{ml} 72 \% \mathrm{H}_{2} \mathrm{SO}_{4}$. Another $20 \mathrm{ml} 72 \% \mathrm{H}_{2} \mathrm{SO}_{4}$ was then added to make the final volume $25 \mathrm{ml}$. This mixture was kept at room temperature for 2 hours. The sulfuric acid treated sample was diluted with $580 \mathrm{ml}$ distilled water in a $1000 \mathrm{ml}$ round bottom flask. Diluted sample was again refluxed for 4 hours. After refluxing, the mixture was cooled and filtered through a sintered G-4 crucible and washed thoroughly to remove all the residual acid. The sintered G-4 crucible with the residues was dried at $105^{\circ} \mathrm{C}$ in a hot air oven for 5-8 hours for complete moisture removal till a constant weight was obtained. The residue obtained after this treatment is lignin and the lignin content of coir fibre was calculated as follows

Lignin content $=$ Weight of lignin $($ in grams) $\times 100$

Weight of sample taken

(Stephen Y.Lin \& Carlton W.Dence(Eds.), 1992)

\section{Evaluation of Brightness Index}

Brightness index (TAPPI 452 / ISO 2470) of the raw, control and treated samples were measured using Premier Colorscan Spectrophotometer in the visible wave length (360-700nm) range.

\section{Physico-Chemical Parameters of Bleach Liquor}

$\mathrm{pH}$, Biological Oxygen Demand (BOD), Chemical Oxygen Demand (COD) and Phenol content of the bleach liquor were estimated using standard methods. (Standard Methods for the examination of water and waste water, 1989).

\section{Results and discussion}

The observations of the bio-bleaching study are furnished in Figure 1. It was observed that 72 hour treatment with Trametes versicolor considerably improved the brightness of the coir yarn. The treatment with bacterial consortium revealed comparatively less bleaching effect. The coir yarn treatment with the cell free culture fluid of $T$. versicolor also displayed the same degree of brightness to the yarn, which confirms the presence of extra-cellular lignin degrading enzymes in the culture fluid. 
Figure 1. Control (left), Fungal (middle) and Bacterial treatment (right) on coir yarn

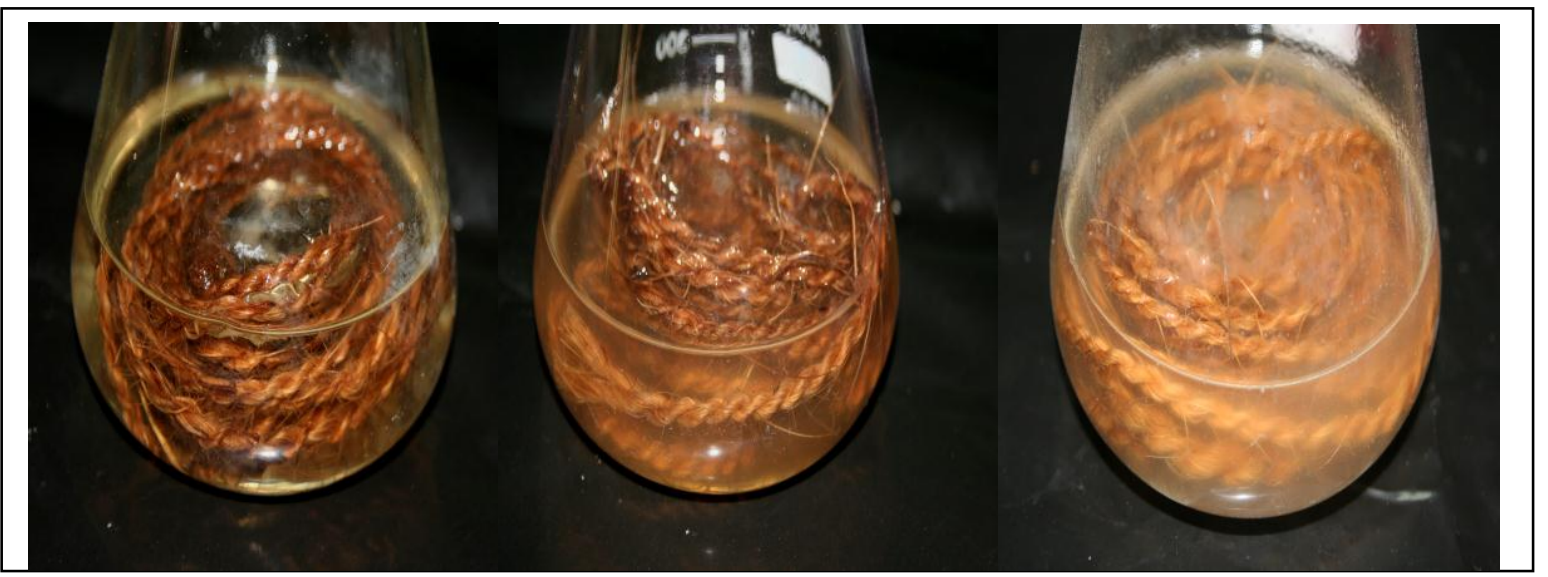

Figure 2. Flexural rigidity change on biosoftening

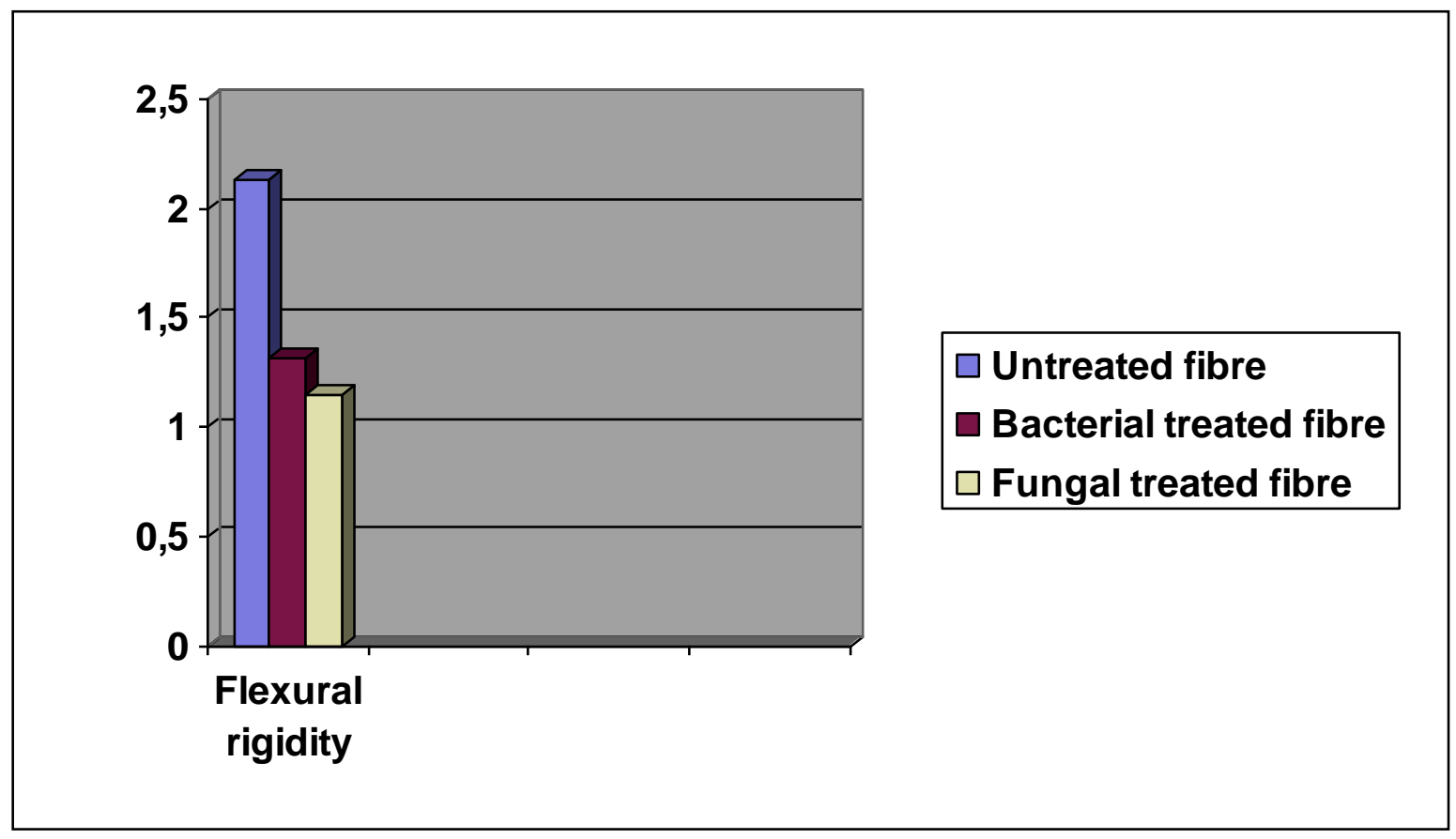


The coir yarn obtained after the chemical bleaching was observed to be rougher in texture than the unbleached yarn. The shade of the chemical bleached yarn was taken as the standard for evaluation of the chemical reduction trials.

\section{Assessment of Softness-Flexural Rigidity Test}

Both the bacterial and fungal treatments were found to be capable of imparting softness to the coir fibre. Apart from improved sensory perception in the feel of the fibre, the flexural rigidity test confirmed the softness. FR values obtained were $2.13 \mathrm{gcm}^{2}$ for raw fibre, $1.32 \mathrm{gcm}^{2}$ for bacterial treated fibre and $1.15 \mathrm{gcm}^{2}$ for fungal treated fibre. Almost 38\% reduction in flexural rigidity of the yarn was observed after bacterial treatment whereas the fungal treatment showed a reduction of $46 \%$ without any loss in strength of the fibre. Reduction in flexural rigidity is directly proportional to the improvement in softness. The result can be interpreted as a bar diagram as shown in figure 2 .

\section{Scanning Electron Microscopic Study}

Samples of untreated, control, bio-bleached and chemical bleached coir yarn/fibre were scanned at different magnifications to examine the changes in surface structure on bleaching. Details of SEM studies are furnished in Figures 3,4 and 5. Fig. 3 portrays the normal and crosssectional view of the untreated fibre. A thin layer of cuticle can be observed all over the surface of the fibre in the case of untreated and control fibres. This layer was absent in the chemical as well as bio-treated fibres.

Another important finding was the appearance of pores on the surface of the treated fibre, which was not observed in the control and untreated fibres. The distribution of pores was higher in chemical bleached fibre, followed by fungal and bacterial bleached fibre. This indicated that bleaching modifies the surface topology of the fibre to some extent.

\section{Variation in Lignin Content}

Lignin content (Klason lignin) of the treated and untreated yarn was estimated by Acid Hydrolysis method and the results are furnished in Table 2. There was no significant difference in the lignin content of the untreated and bacterial treated yarn. However, the lignin content of fungal treated yarn was observed to be $32 \%$, which was around $12 \%$ lower than that of the lignin content of untreated yarn. The lignin content of chemical bleached yarn was 23\% lower than that of the untreated yarn.

Table 2. Lignin content of bio-treated coir yarn

\begin{tabular}{|l|c|}
\hline \multicolumn{1}{|c|}{ Samples } & Lignin content (\%) \\
\hline Untreated yarn & 36.270 \\
\hline Bacterial treated yarn & 36.268 \\
\hline Fungal treated yarn & 32.070 \\
\hline Chemical bleached yarn & 28.590 \\
\hline
\end{tabular}

\section{Chemical Reduction Trials}

Bio-bleaching was evident in fungal bleached coir yarn as the brightness was significant over the control yarn. The fungal treated yarn (CRT-A) bleached with the same amount of chemicals was found to be brighter than the chemical bleached yarn. Hence the chemical reduction trials were carried out on the fungal treated coir yarn. Three reduction trials were carried out with $2.4 \%, 4 \%$ and $8.8 \%$ reduction in the usage of chemicals. The yarn obtained after the combined bleaching trials retained the same brightness as that of chemical bleached yarn. To confirm the visual assessment, the brightness index of the treated yarn was also evaluated (CRT-B, CRT-C and CRT-D).

\section{Evaluation of Brightness Index}

The colour/brightness of the yarn was quantified in terms of Brightness Index using Premier scan Spectrophotometer. Brightness index of the untreated yarn was observed to be 10.093. Fungal treatment increased the brightness index by a factor of 0.97 ie 11.063 . Brightness of the chemically bleached yarn was 18.507. The chemical reduction trials (CRT) were assessed in terms of brightness index, so as to retain the same degree of brightness. The brightness index of the fungal treated yarn bleached with the same amount of chemicals 
Figure 3. Scanning Electron Microscope image of Untreated fibre (Normal view \& Cross sectional view)

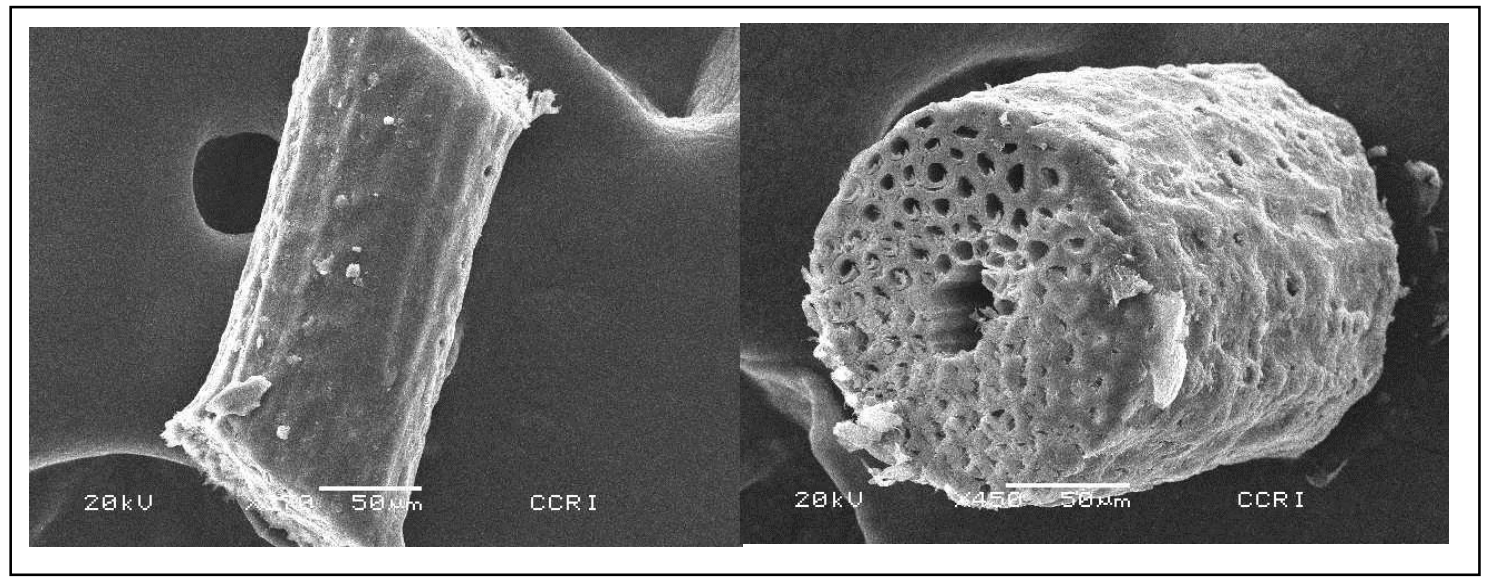

Figure 4. Scanning Electron Microscope image of Control fibre (left) and Chemical bleached fibre (right)

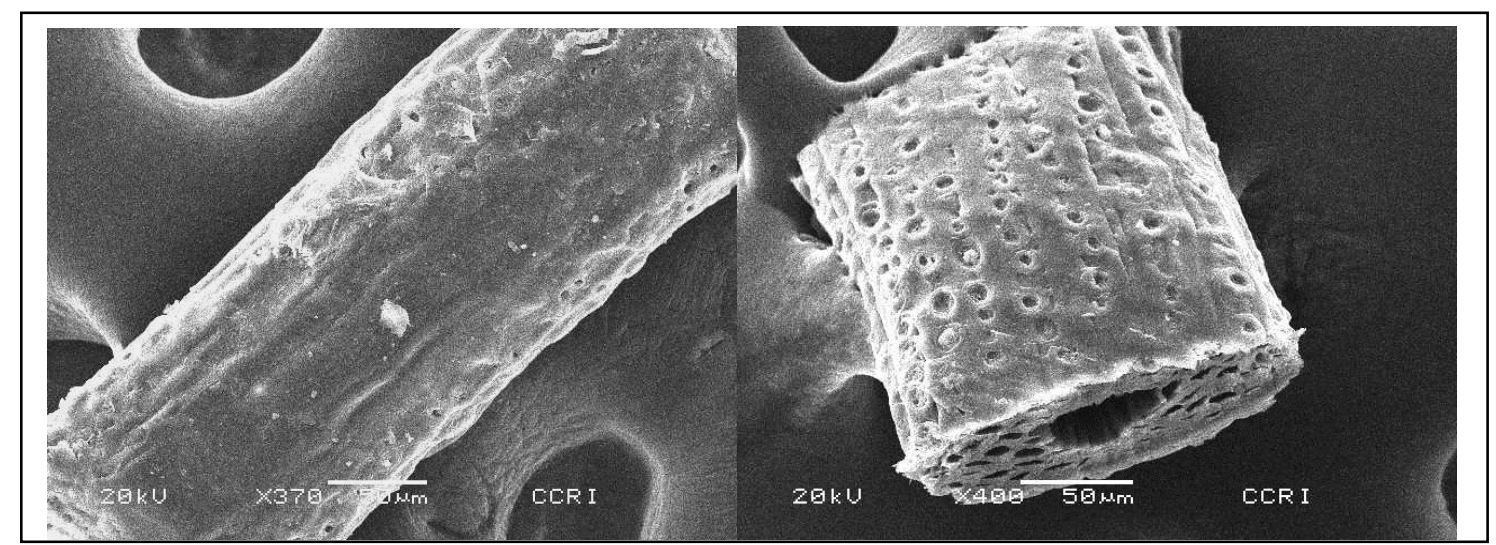

Figure 5. Scanning Electron Microscope image of Bacterial treated fibre (left) and Fungal treated fibre (right)

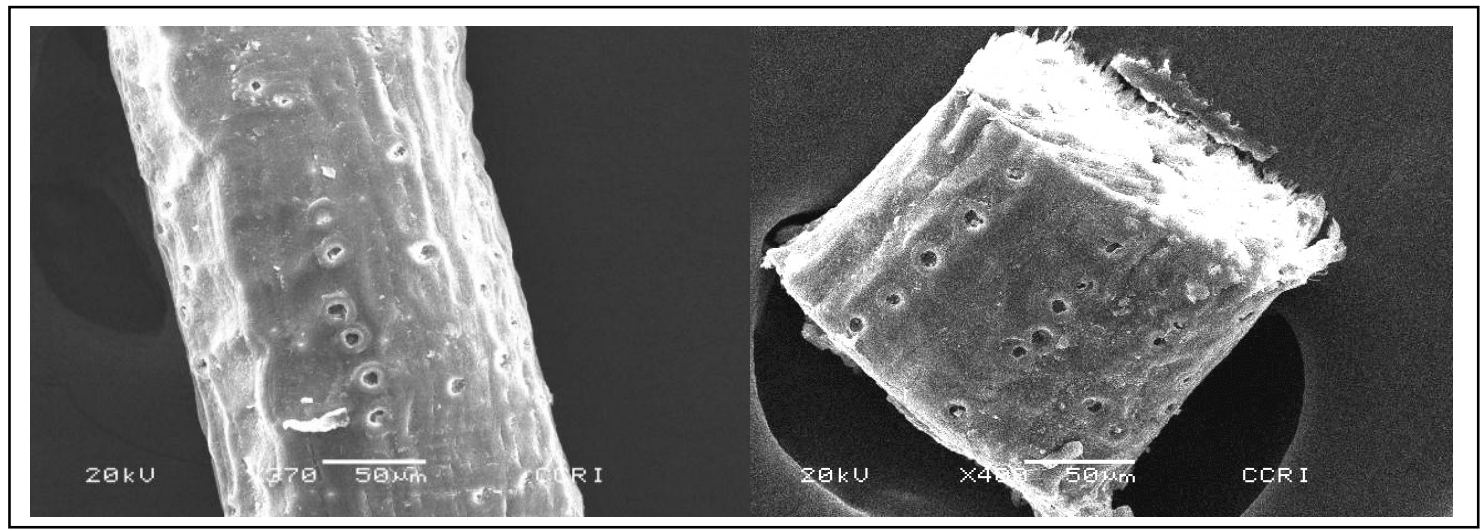


was 19.978 which was higher than that of the chemical bleached yarn. The coir yarn after combined bleaching was found to have the brightness index close to that of 18.507, the brightness index of chemical bleached yarn. Data on the brightness index of different samples have been furnished in Table 3 .

Table 3. Brightness index of treated yarn

\begin{tabular}{|c|c|}
\hline Sample & Brightness Index \\
\hline Untreated yarn & 10.093 \\
\hline Control yarn & 9.766 \\
\hline Bacterial treated yarn & 9.351 \\
\hline Fungal treated yarn & 11.063 \\
\hline Chemical bleached yarn & 18.507 \\
\hline CRT-A & 19.978 \\
\hline CRT-B & 19.197 \\
\hline CRT-C & 18.128 \\
\hline CRT-D & 18.305 \\
\hline
\end{tabular}

\section{Analysis of Bleach Liquor}

To evaluate the status of the effluent after bio-bleaching, different physico-chemical parameters of the residual bleach liquor were studied. pH, Biological Oxygen Demand (BOD), Chemical Oxygen Demand (COD) and phenol content were estimated to analyse the pollution aspects of bleaching. The results obtained are tabulated in Table 4. It was observed that, when compared to chemical bleaching, the bio-bleach liquor possessed lower BOD, COD and phenol content, thereby confirming that the process leads to reduction in pollution. Combined bleaching or bleaching of fungal treated coir yarn with lesser quantity of chemicals, have considerably reduced the BOD, COD and phenol content of the bleach liquor indicating the advantage of combined bleaching over chemical bleaching.

Although the use of Trametes versicolor for paper pulp bio-bleaching has been well studied there is no literature available on the application of Trametes versicolor for biobleaching and bio-softening of coir yarn. In the present study the bio-bleaching potential of Trametes versicolor on coir yarn was evaluated and the observations confirm its potential for bio-bleaching and bio-softening of coir yarn.

Flexural rigidity test indirectly measures the degree of softness by evaluating the flexural rigidity of the fibre, when subjected to deformation. Coir yarn treatments with both the bacterial and fungal cultures were observed to impart a smoother feel to the yarn. Softening of $46 \%$ by fungal treatment and $38 \%$ by bacterial treatment was achieved. This was remarkably higher than the softening reported in a study on softening of coir fibre using different chemical softeners where the maximum softening $(24.65 \%)$ was obtained using sodium hydroxide. (Anto, et al, 1997b) Since the rigid lignin network between fibre cells restricts its flexible behavior, softening might have occurred as a result of the degradation of surface lignin.

SEM studies of coir yarn could help in understanding the difference in surface structure brought about by bleaching. The appearance of pores on the treated yarn is an indication of the removal of lignin bondage between the cellulose strands. The effect of bleaching was greater in chemical bleaching as also the extent of pore formation. However this may not affect the strength of the fibre/yarn, since the degradation takes place only on the surface of the fibre.

The fact that reduction in lignin content leads to bio-bleaching and bio-softening the fungal treated yarn is evident since the component responsible for colour and stiffness of coir yarn are one and the same 'lignin'. Chemical bleached yarn retained $28 \%$ of its lignin content, which indicates that the action of chemicals is restricted to the surface of the yarn. Similarly, microbial activity was also confined to the fibre surface. The degree of biological delignification can be enhanced by the direct application of lignolytic enzymes secreted by the microorganisms.

A bio-bleaching using fungus was insufficient to achieve the required brightness of the yarn. A combination of fungal and reduced chemical treatment demonstrated the maximum potential of bio-bleaching. Apart from the reduction in pollution load this has an additional advantage of being cost effective. 
Table 4. Physico-chemical parameters of bleach liquor

\begin{tabular}{|l|c|c|c|c|}
\hline TREATMENT & pH & $\begin{array}{c}\text { PHENOL } \\
\text { Concentration } \\
(\mathbf{m g} / \mathbf{l})\end{array}$ & $\begin{array}{c}\text { BOD } \\
(\mathbf{m g} / \mathbf{l})\end{array}$ & $\begin{array}{c}\text { COD } \\
(\mathbf{m g} / \mathbf{l})\end{array}$ \\
\hline Control & 7.65 & 2.656 & 38.50 & 1111.04 \\
\hline Bacterial treatment & 7.37 & 7.584 & 263.54 & 912.64 \\
\hline Fungal treatment & 4.44 & 10.784 & 709.46 & 7022.40 \\
\hline Chemical bleaching & 9.35 & 74.700 & 1246.62 & 4435.20 \\
\hline Combined bleaching & 9.60 & 64.700 & 844.56 & \\
\hline
\end{tabular}

BOD, COD, phenol content and $\mathrm{pH}$ are some of the important physico-chemical parameters of the effluents from the coir industry that are to be monitored continuously. The phenolic constituents present in the residual liquor are toxic in nature and are detrimental to the survival of aquatic organisms. Thus its concentration in the bleach liquor should be as low as possible. The residual bleach liquor after combined bio- chemical treatment of the yarn exhibited decreased levels of phenol, BOD and COD, which is desirable. The BOD of the fungal treatment liquor can be reduced further by applying lignolytic enzymes extracted from culture broth instead of applying the whole cell culture.

In a report on softening of coir yarn conducted at CCRI, caustic soda has been used as the softening agent. Even though caustic soda treatment was found to be quite effective in producing the crimp on the fibre, the colour of the fibre was changed into deep brown. The effluent treatment was another big problem to tackle as the residual alkali needed to be neutralized with huge quantities of inorganic acids making the process hazardous and uneconomical. Therefore, it was rejected by the coir industry. (Sarma, 2001). Thus bio-softening of coir yarn has a better edge over chemical softening in the aspects of pollution control and cost. In biological treatment, the toxic lignin degradation products like phenols are not only removed from the coir but are consumed by the microorganisms, thus reducing the toxicity of the effluent. This in turn reduces the COD, phenol content and other pollution parameters of the effluent.

The present study indicates that the pretreatment of coir yarn with $T$. versicolor followed by chemical processing could be an economical alternative for bleaching in the coir industry. The wet processing technology, which may be adopted by this combined bio-chemical bleaching, will also lead to the reduction in pollution load released as effluent to the water bodies.

The salient findings of this study pave the way to the development of an eco-friendly process for biobleaching and biosoftening that can be adopted in the wet processing of coir.

\section{Acknowledgement}

The authors express their gratitude to Dr. U.S. Sarma, Director, RDTE, of Central Coir Research Institute for his keen interest and encouragements to carry out this work. 


\section{References}

Akhila Rajan and T. Emilia Abraham. 2007. Coir Fibre-Process and Opportunities: Part 2. Journal of natural fibres. 4(1):1-11.

Ana Maria Rebelo Barreto Xavier, Ana Paula Mora Tavares, Rita Ferreira, Francisco Amado. 2007. Trametes versicolor growth and laccase induction with by-products of pulp and paper industry. Electronic Journal of Biotechnology. 10(3):

Anto, I.R, Ravindran, T, Ravi, P.K, Kumaraswamy Pillai, M and Sharma, U.S. 1997a. Investigations in Bleaching of Coir. Proceedings on the International Workshop on Wet Processing of Coir, COIR' 97. : 86-99

Anto, I.R, Ravi, P.K, Sharma, U.S. 1997b. Studies on imparting softness to coir fibre/yarn. Proceedings on the International Workshop on Wet Processing of Coir, COIR' 97. :68-85

Arockiasamy S, Krishnan IP, Anandakrishnan N, Seenivasan S, Sambath A, Venkatasubramani JP. 2008. Enhanced production of laccase from Coriolus versicolor NCIM 996 by nutrient optimization using response surface methodology. Appl Biochem Biotechnol. 151(2): 371-379

Arora, Daljit Singh and Gill, Paramjit Kaur. 2001. Effects of various media and supplements on laccase production by some white rot fungi. Bioresource Technology. 77(1): 89-91

Das, A.R. 2001. Biotechnology in coir extraction and waste utilization. CORD. 17(2)

Gupta. P.K. 2001. Methods in Environmental Analysis: Water, Soil and Air. Agrobios (India), pp. 68-72

Hiroto Homma, Hirofumi Shinoyama, Yukihiro Nobuta,Yoshie Terashima, Seigo Amachi and Takaaki Fujii. 2007. Lignindegrading activity of edible mushroom Strobilurus ohshimae that forms fruiting bodies on buried sugi (Cryptomeria japonica) twigs. Journal of Wood Science. 53(1): 80-84

Nurdan Kasikara Pazarlıoglu, Merih Sariisik and Azmi Telefoncu. 2005. Laccase: production by Trametes versicolor and application to denim washing. Process Biochemistry. 40(5): 1673-1678

Rajan A, Senan RC, Pavithran C, Abraham TE. 2005. Biosoftening of coir fibre using selected microorganisms. Bioprocess Biosyst. Eng. 28(3): 165-173

Stephen Y. Lin \& Carlton W. Dence (Eds.). 1992. Methods in Lignin Chemistry, Springer -Verlag Berlin Heidelberg, pp. $34-40$

Standard Methods for the examination of water and waste water. 1989. APHA-AWWAWPCF, $17^{\text {th }}$ Edition, American Public Health Association, pp.5.48-5.54.

Suganya, D.S, Pradeep, S, Jayapriya, J and Subramanian, S. 2007. Bio-softening of mature coconut husk for facile coir recovery Bio-softening of mature coconut husk for facile coir recovery. Indian Journal of Microbiology. 47(2)

Uma Sankar Sarma. 2001. Softening of coir' Souvenir, published by Coir Board on the occasion of India International Coir Fair (IICF), pp. 103-109 